\title{
Maximum power point tracking of partially shading PV system using cuckoo search algorithm
}

\author{
A. Ibrahim ${ }^{1}$, Raef Aboelsaud ${ }^{2}$, S. Obukhov ${ }^{3}$ \\ 1,2 Department of Electrical Power and Machines Engineering, Zagazig University, Egypt \\ 1,2,3 Department of Energy and Power Engineering, National Research Tomsk Polytechnic University, Russia
}

\begin{tabular}{l} 
Article Info \\
\hline Article history: \\
Received Dec 8, 2018 \\
Revised Mar 3, 2019 \\
Accepted Mar 12, 2019 \\
\hline
\end{tabular}

\section{Keywords:}

Global maximum power point Maximum power point tracking Cuckoo search

Partially shading condition

\begin{abstract}
This paper presents a cuckoo search (CS) algorithm for determining the global maximum power point (GMPP) tracking of photovoltaic (PV) under partial shading conditions (PSC). The conventional methods are failed to track the GMPP under PSC, which decrease the reliability of the power system and increase the system losses. The performance of the CS algorithm is compared with perturb and observe $(\mathrm{P} \& \mathrm{O})$ algorithm for different cases of operations of PV panels under PSC. The CS algorithm is used in this work to control directly the duty cycle of the DC-DC converter without proportional integral derivative (PID) controller. The proposed CS model can track the GMPP very accurate with high efficiency in less time under different conditions as well as in PSC.
\end{abstract}

Copyright (C) 2019 Institute of Advanced Engineering and Science. All rights reserved.

\section{Corresponding Author:}

A. Ibrahim

Departement of Electrical Power and Machines Engineering,

Zagazig University, Egypt.

Email: ibragim@tpu.ru

\section{INTRODUCTION}

It is known that the world's electricity consumption will increase annually it is expected that further growth will be due to the increase in the number of population and the increasing demands of the modern way of lifestyle $[1,2]$. Therefore, there is a need to develop renewable energy sources to ensure sustainability high power supplies to the consumer, as well as to reduce local and global room pollution. The main problems in the practical use of Pa V power generation system (PGS) are the relatively low efficiency of conversion of primary energy (from 9 to $17 \%$ ) and the pronounced dependence of the solar cell's energy characteristics on external climatic conditions [3-5]. Solar panels consist of several series-parallel connected solar modules and are designed for direct conversion of solar energy into electrical energy with the necessary values of constant voltage and current.

The power characteristics of solar cells have a nonlinear convex shape with an extremum, so to obtain the maximum available power it is advisable to operate them at the maximum power point (MPP). On the other hand, the generated power of solar panels depends on the operating conditions: the intensity of solar radiation, ambient temperature [6]. Changing in one or all of these conditions will lead to change in the position of MPP. So the search and tracking of MPP in real operating conditions are one of the ways to improve the operational efficiency of the solar panel. With no Shading, many conventional methods of having been developed for MPPT, the most common methods among them are a constant voltage MPPT, perturb and observe (P\&O) and its numerous modifications, and incremental inductance method [7-11]. Under partial shading, the P-V characteristic has many local peaks and one global peak [12-14]. The conventional methods are failed to track the GMPP. Recently, the researchers have worked how to track the GMPP under PSC using soft computing techniques. 
Among them are the fuzzy logic control (FLC) [15], artificial neural networks (ANN) [16], Genetic algorithm (GA) [17], particle swarm optimizations (PSO) [18] and ant colony optimizations [19]. They test the performance of their algorithms under dynamic changes of the solar irradiance of the PV panel. Although the very high cost of implementation the ANN and fuzzy logic, they capable of tracking the GMPP with lower oscillation in power as compared to $\mathrm{P} \& \mathrm{O}$ algorithm. The major difference between the proposed CS and other techniques is that the proposed algorithm is used to control the duty cycle directly without using the without Proportional Integral Derivative (PID) controller [20].

In this paper, the CS algorithm is introduced to track the GMPP of the PV under fast variation of solar irradiance as well as partial shading condition. The proposed algorithm is compared with the P\&O algorithm in different test cases and the efficiency of both of them are measured in each test case. Section two describes the modeling of single diode PV cell. The effect of PSC on PGS is explained in section three. Section four describes the CS and P\&O and its applications in PSC. Simulation results of the developed model are explained in the sixth section.

\section{SINGLE DIODE PV MODEL}

A single diode equivalent circuit is the most common mathematical model of PV arrays that available in the literature. Figure 1 illustrates the equivalent circuit of the PV cell that used in the proposed model.

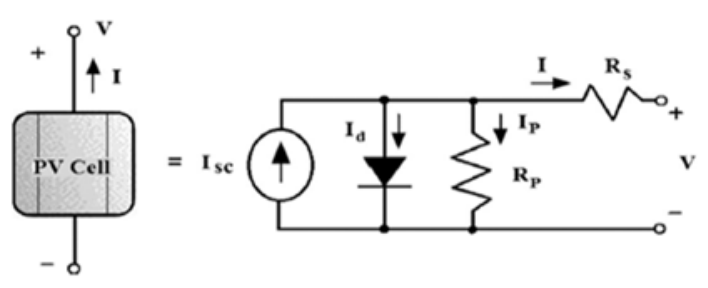

Figure 1. The equivalent circuit of a solar cell

The output current of the PV cell is calculated by the following equations [21]:

$$
\begin{aligned}
& I=I_{s c}-I_{D}-I_{p} \\
& I=I_{s c}-I_{0} \cdot\left[\exp \left(\frac{q\left(V+I \cdot R_{S}\right)}{n \cdot k \cdot T}\right)-1\right]-\frac{V+I \cdot R_{S}}{R_{p}}
\end{aligned}
$$

Where, V, I - is the value of output voltage and current of the PV cell; $I_{o}$ - reverse saturation current of the diode; $R_{S}$ и $R_{p}$ series and parallel resistance of the solar cell; $\mathrm{n}$ is the ideality factor; Т- is the absolute temperature of the PV cell; $\mathrm{k}=1.38 \cdot 10^{-23} \mathrm{j} / \mathrm{k}$ Boltzmann constant.

A PV module consists of a large number of identical solar cells connected in series and in parallel, which allows increasing its voltage and output power. The main electrical parameters of the PV module that used in this work are summarized in Table 1.

Table 1. Specifications of PV Module

\begin{tabular}{cc}
\hline \multicolumn{2}{c}{ Table 1. Specifications of PV Module } \\
\hline Parameter & Value \\
\hline Maximum power rating $\mathrm{P}_{\max }$ & $249 \mathrm{w}$ \\
Rated voltage $\mathrm{V}_{\mathrm{MPP}}$ & $30 \mathrm{~V}$ \\
Open circuit voltage $\mathrm{V}_{\mathrm{OC}}$ & $8.3 \mathrm{~A}$ \\
Short circuit current $\mathrm{I}_{\mathrm{SC}}$ & $8.83 \mathrm{~A}$ \\
Rated current $\mathrm{I}_{\mathrm{MPP}}$ & $36.8 \mathrm{~V}$ \\
Temperature coefficient of $\mathrm{I}_{\mathrm{sc}}$ & $(0.065 \pm 0.015) \% /{ }^{\circ} \mathrm{C}$ \\
Temperature coefficient of power & $-(0.5 \pm 0.05) \% /{ }^{\circ} \mathrm{C}$ \\
\hline
\end{tabular}

Int J Pow Elec \& Dri Syst, Vol. 10, No. 2, June 2019 : 1081 - 1089 


\section{PV MODULE UNDER PSC}

In real operations, the PV modules are often subject with PSC, which resulted from clouds; trees; buildings; towers. As an example to show the effect of the shading on the PV module, four PV panels are connected in series. This configuration is named " $4 \mathrm{~s} 1 \mathrm{p}$ " connection, as shown in Figure 2. To simulate that model in Matlab, PV output current is supplied to DC voltage controlled source as shown in Figure 3. The P$\mathrm{V}$ and $\mathrm{V}-\mathrm{I}$ for these cases are shown in Figure 4.

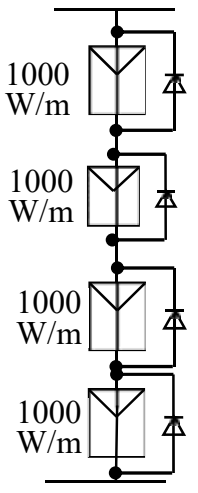

Normal Irradiance

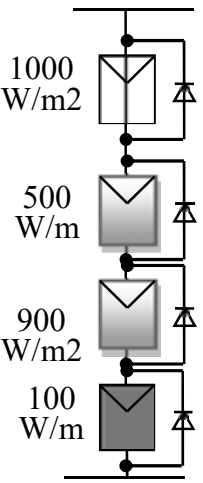

Partial Shading

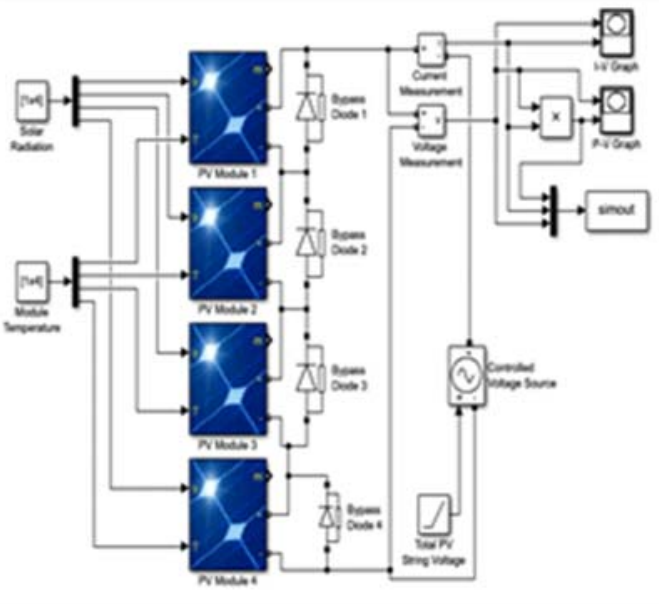

Figure 2. Normal Irradiance and PSC of PV panels

Figure 3. Interfacing mathematical PV module model to physical ports

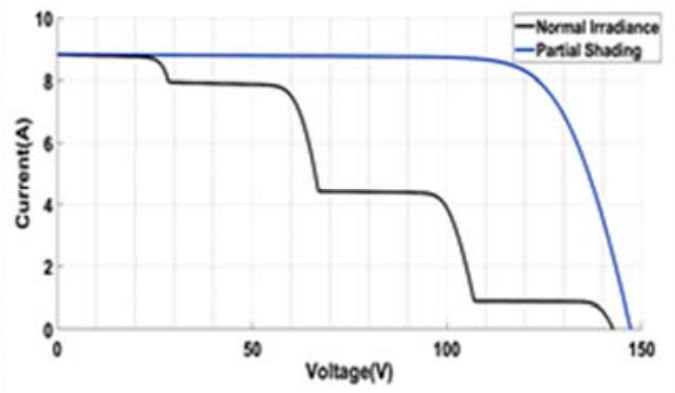

Figure 4. The P-V and V-I characteristics of PV panels under PSC

The current generated by PV under PSC is not constant. In case of normal irradiance of the PV panels, a constant current of approximately $8.3 \mathrm{~A}$ is generated at a functional operating voltage of $0 \mathrm{~V}$ to 120 $\mathrm{V}$ as shown in Figure 4. However, when the PV is under the PSC, the generating current cannot maintain a constant value. For example, in PSC, PV generates constant current $8.3 \mathrm{~A}$ from $0 \mathrm{~V}$ to $25 \mathrm{~V}$, then decreases to $8 \mathrm{~A}, 4.1 \mathrm{~A}$ and $1.6 \mathrm{~A}$ at $55 \mathrm{~V}, 100$ and $120 \mathrm{~V}$, as shown in Figure 4. The PSC case demonstrate four peaks because it receives four different levels of irradiation.

\section{CUCKOO SEARCH (CS)}

Cuckoo Search (CS) was first developed by [Yang \&Deb] [22]. These algorithms usually work based on a random search, which simulates the reproduction strategy of cuckoo birds. It is observed that several species of cuckoos perform brood parasitism, i.e. by laying their eggs in host birds' nests. Usually, three types of brood parasitism are seen (1) intraspecific, (2) cooperative and (3) nest takeover. Some host birds engage in direct conflict with the intruding cuckoos. If a host bird discovers the cuckoo eggs it will

Maximum power point tracking of partially shading PV system using Cuckoo Search ... (A. Ibrahim) 
throw these alien eggs away or abandons its nest and builds a new nest elsewhere. Some cuckoo species have evolved in such a way that female parasitic cuckoos mimic the shape and color of the eggs of a few chosen host species. To increases its reproduction probability.

\subsection{Lévy flight}

Searching for a suitable host bird's nest is an important part of cuckoo's reproduction strategy. Normally, the search for the nest is similar to the search for food, which takes place in a random or in a quasi-random form. In general, while searching for food, animals choose directions or trajectories that can be modeled by certain mathematical functions. One of the most common models is the Lévy flight. A recent study by Reynolds and Frye shows that a Lévy flight can be thought of as a random walk where the step size has a Lévy probability distribution. In CS, nest searching is characterized by Lévy flight. Mathematically, a Lévy flight is a random walk where step sizes are extracted from Lévy distribution according to a power law as shown below [23]:

$$
y=l^{-\lambda}
$$

Where $l$ is the flight length and $\lambda$ is the variance. Since $1<\lambda<3$, y has an infinite variance. Figure 5 shows an example of Lévy flight in a two-dimensional plane.

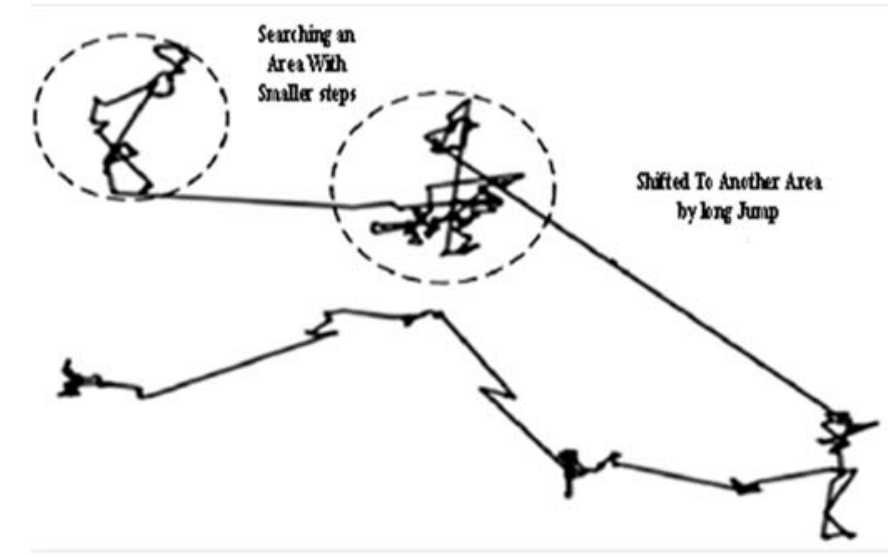

Figure 5. Example of Lévy flight in a two-dimensional plane

\subsection{Cuckoo search algorithm}

Three idealized rules for CS based on cuckoo's brood parasitic behavior: (1) Each cuckoo lays one egg at a time and places it in a randomly chosen nest (2) The best nest with the highest quality of eggs will be carried over to the next generation (3) The number of available nests is fixed and the number of cuckoo eggs discovered by the host bird maintains a probability $\mathrm{Pa}$, where $0<\mathrm{Pa}<1$. When generating a new solution for a cuckoo, a Levy flight is performed as in the following expression [24] [25]:

$$
x_{i}^{(t+1)}=x_{i}^{t}+\alpha \oplus \operatorname{Lévy}(\lambda)
$$

Where $x_{i}^{t}$ are samples/eggs, $\mathrm{i}$ is the sample number, $\mathrm{t}$ is the number of iteration and $\alpha$ is the step size, which is related to the scales of the problem of interests. In most cases, we can use $\alpha=1$. The product $\oplus$ means entry wise multiplications. The value of $\alpha$ is calculated by the following equation:

$$
\alpha=\alpha_{0}\left(x_{j}^{(t)}-x_{i}^{(t)}\right)
$$

The value of Lévy $(\lambda)$ is found from Lévy distribution given in Eq. 7

$$
\text { Lévy }(\lambda) \approx u=l^{-\lambda}
$$

Int J Pow Elec \& Dri Syst, Vol. 10, No. 2, June 2019 : 1081 - 1089 


\section{MPPT USING CS}

All the voltages are provided to the PV panels and the output power are calculated by the proposed model. The fitness function in CS is considered to be the output duty cycle that will fed to the Dc-DC boost converter at the GMPP of the PV panels, the $d_{\text {best }}$ is the best one among the fitness. The duty cycle is changed in CS by the following equation:

$$
d_{i}^{(t+1)}=d_{\text {best }}{ }^{t}+\alpha \oplus \operatorname{Lévy}(\lambda)
$$

Where, $d_{1}=d_{1}, d_{2} \ldots n$

A simplified scheme of the Lévy distribution can be explained by:

$$
s=\alpha_{0}\left(d_{b e s t}-d_{i}\right) \oplus \operatorname{Lévy}(\lambda) \approx k \times\left(\frac{u}{\left(\mid v^{\mid \frac{1}{\beta}}\right)}\right)\left(d_{b e s t}-d_{i}\right)
$$

Where, $\mathrm{n}=4, \beta=1.5$ and $k=0.8$ is the Lévy multiplying coefficient (chosen by the designer), while $\mathrm{u}$ and $\mathrm{v}$ are determined from the normal distribution curves. in Figure 6.

The flow chart of CS that illustrates how to use the algorithm to get the MPP of solar panel is shown

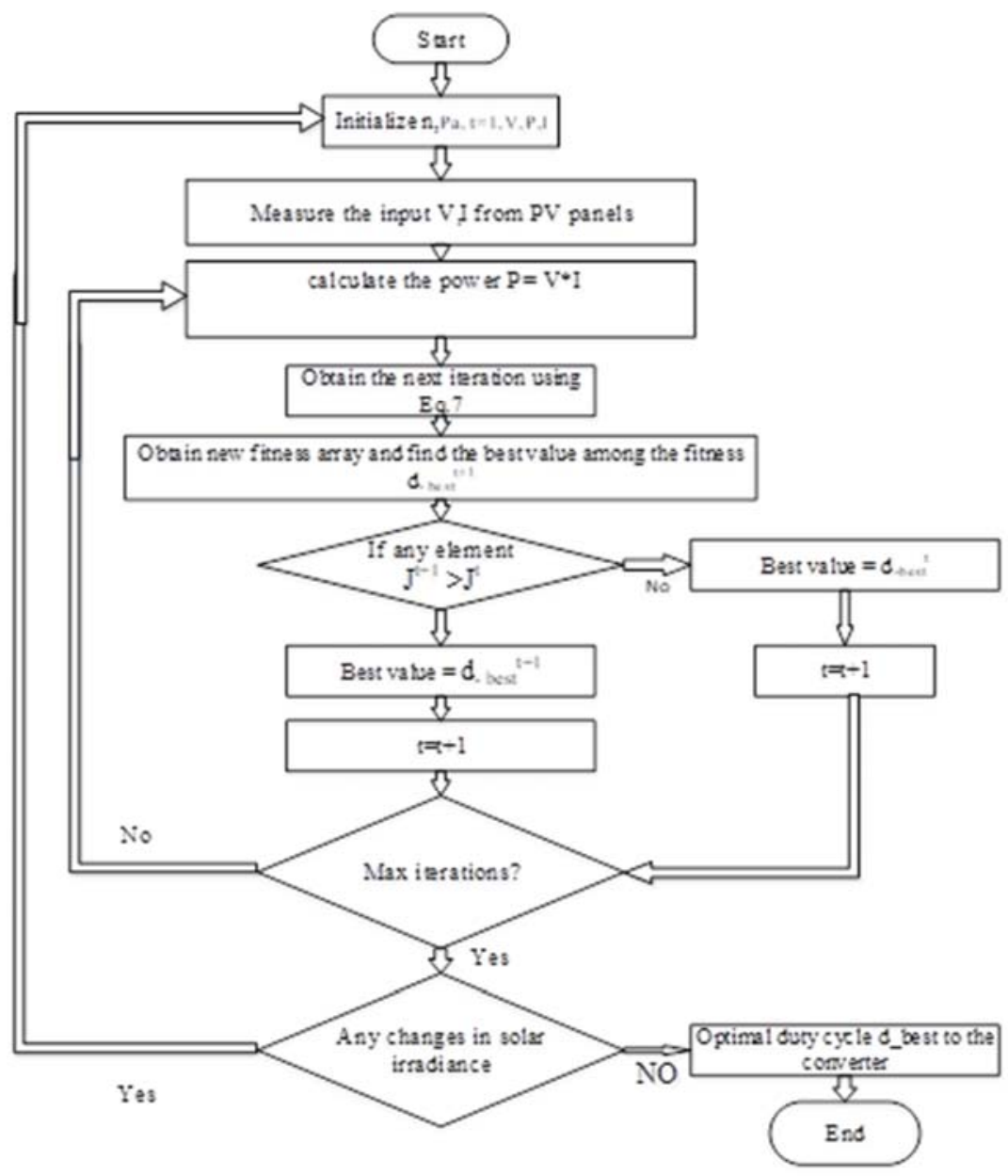

Figure 6. The flowchart of the CS algorithm 


\section{SIMULATIONS RESULTS}

The proposed model is carried out in the Matlab/Simulink program software as shown in Figure 7. The DC-DC boost converter is selected in the proposed work to match the MPP controller with a resistive load. The selected parameters of the converter are;

$\mathrm{L}=1.1 \mathrm{mH} ; \mathrm{c}_{1}=0.4 * 10^{-4} \mathrm{~F}, \mathrm{c}_{2}=0.4 \mathrm{mF}$ and switching frequency $\mathrm{f}=25 \mathrm{kHz}$. The criteria for stopping the iterative process of calculations are the maximum number of iterations and the relative error in calculating the global extremum of the objective function:

$$
\varepsilon=\frac{P_{b e s t}^{i+1}-P_{b e s t}^{i}}{P_{b e s t}^{i}} \cdot 100<0.3
$$

Figure 8 and 9 show the performances of the CS and P\&O for determination the GMPP of the PV under normal irradiance of the solar panels and in case of PSC that was shown in Figure 2. The following equation is used for evaluating the efficiency of the two algorithms in all cases

$$
\eta=\frac{P_{0}}{P_{\max }} \cdot 100, \%
$$

Where $P_{0}$ is the value of the output power of the PV panel, that tracked by the algorithm; $P_{\max }$ - the value of the maximum available power.

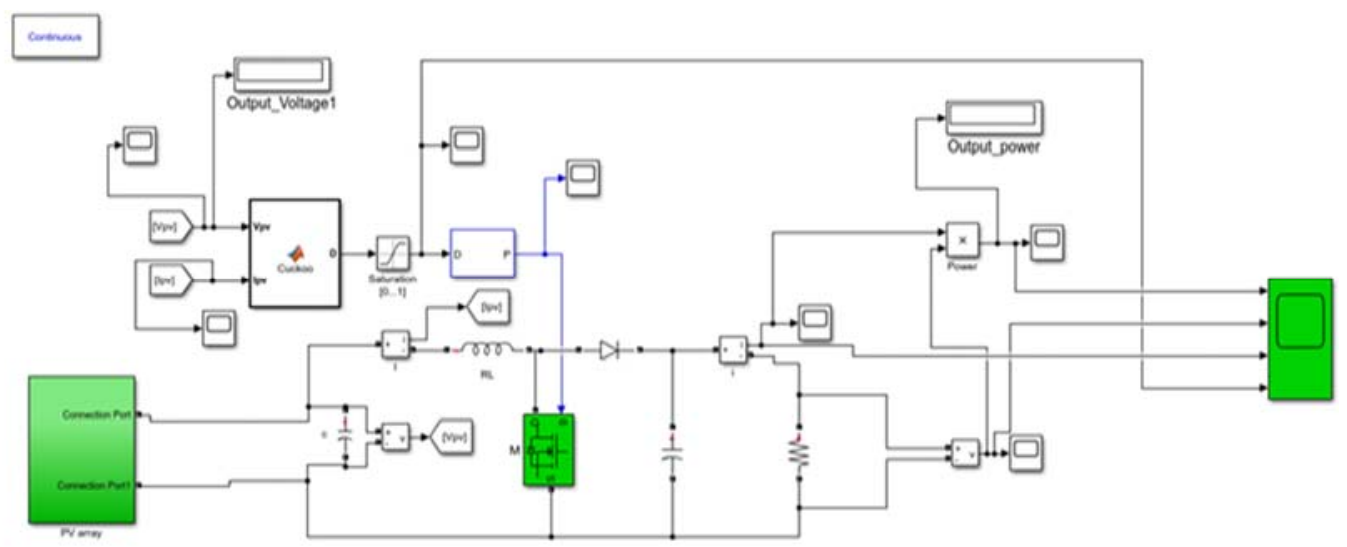

Figure 7. MATLAB/Simulink of the proposed model

As illustrated in Figure 8 the CS algorithm is able to track the GMPP of the solar panel after only four iterations the optimal duty cycle was $\left(\mathrm{d}_{\text {best }}=0.47\right)$ and the tracking time was $0.32 \mathrm{sec}$. Also in case of PSC the proposed algorithm tracked the global peak, while the $\mathrm{P} \& \mathrm{O}$ algorithm trapped in local peak which increase the system losses and reduce the reliability of the PV plant.

(a)

Figure 8. The performance of the two algorithms in the normal case (a) CS (b) P\&O 
Figure 9. The performance of the two algorithms in the PSC (a) CS (b) P\&O

\subsection{Fast variation of the solar irradiance under constant temperature}

Case 3 are about the fast variation of the solar irradiance of the PV panel under PSC. In case 3, as illustrated in Figure 10. From time $\mathrm{t}=0$ to $\mathrm{t}=1 \mathrm{sec}$ all PV panels received the same amount of the solar irradiance $\mathrm{G}=1000 \mathrm{w} / \mathrm{m} 2$, after $\mathrm{t}=1 \mathrm{sec}$ the PSC occurs where, the solar irradiance of the PV panels were $\mathrm{G} 1=1000 \mathrm{w} / \mathrm{m} 2, \mathrm{G} 2=500 \mathrm{w} / \mathrm{m} 2, \mathrm{G} 3=1000 \mathrm{w} / \mathrm{m} 2$ and $\mathrm{G} 4=100 \mathrm{w} / \mathrm{m}$. On the other hand, in case 3 as shown in Figure 10 after shifting from normal operations to PSC, the CS only can handle the GMPP in this case with highly tracking efficiency $(\eta=99.7 \%)$, while the conventional P\&O trapped at the local peak. Also, can be seen, the steady power performance of the CS are very well. Table 2 shows illustrates the detailed comparison between the CS and P\&O for all test cases.

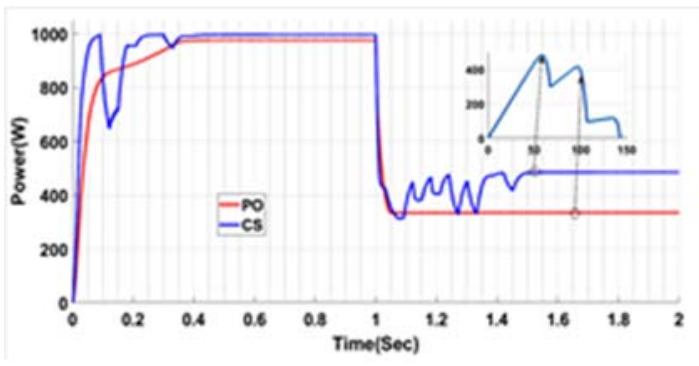

(a)

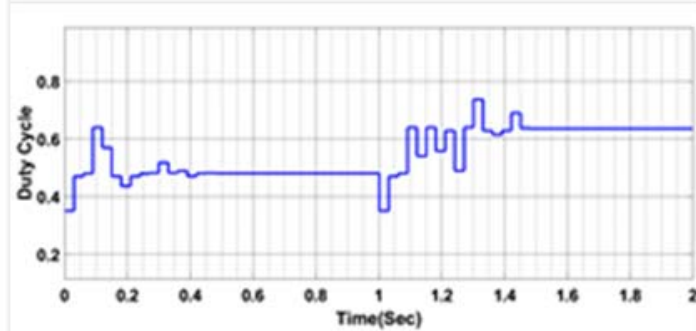

(b)

Figure 10. (a) The performance of CS and P\&O under fast variation of the PV under PSC. (b) duty cycle of the CS algorithm

Table 2. Results of the three cases of studies

\begin{tabular}{|c|c|c|c|c|c|c|}
\hline \multirow[b]{2}{*}{ case studies } & \multicolumn{3}{|c|}{$\mathrm{CS}$} & \multicolumn{3}{|c|}{$\mathrm{P} \& \mathrm{O}$} \\
\hline & $\begin{array}{l}P_{\max }, \\
\text { Watt }\end{array}$ & $\begin{array}{c}P_{0}, \\
\text { Watt }\end{array}$ & $\eta, \%$ & $\begin{array}{l}P_{\max }, \\
\text { Watt }\end{array}$ & $\begin{array}{c}P_{0}, \\
\text { Watt }\end{array}$ & $\eta, \%$ \\
\hline Normal Irradiance & 996 & 995 & 99.8 & 996 & 976 & 97.9 \\
\hline PSC & 452 & 451 & 99.7 & 452 & 331 & 73.9 \\
\hline Dynamic operation with PSC & 484 & 483 & 99.7 & 484 & 334 & 69 \\
\hline
\end{tabular}

\section{CONCLUSIONS}

In this study, the performance of CS algorism investigated to track the GMPP of the solar panel under PSC and compared with the conventional P\&O algorithm. Three different test cases of studies of PV modules are used under PSC to evaluate the performance of the proposed CS algorithm. For all test cases, the tracking efficiency of the CS is higher than $99 \%$ within $300-500 \mathrm{~ms}$. The developed CS algorithm can handle the PSC very efficiently under different shading conditions, while $\mathrm{P} \& \mathrm{O}$ algorithm incapable of handling the PSC of the solar panel. The results also indicate that the tracked power by the CS has a very low fluctuations of the steady power compared to $\mathrm{P} \& \mathrm{O}$ algorithm. The CS has proven accuracy, robustness, and effectiveness of efficient energy utilization for the standalone PV system. 


\section{REFERENCES}

[1] R. Aboelsaud, A. Ibrahim, and A. G. Garganeev, "Review of three-phase inverters control for unbalanced load compensation," International Journal of Power Electronics and Drive Systems (IJPEDS), vol. 10, no. 1, pp. 242 255, 2019.

[2] M. Abdelaziz Mohamed and A. M. Eltamaly, "Modeling of hybrid renewable energy system," in Studies in Systems, Decision and Control, 2018.

[3] Abdelkader Mezouari, R. Elgouri, M. Alareqi, K. Mateur, H. Dahou4, L. Hlou, " A New Photovoltaic Blocks Mutualization System for Micro-Grids Using an Arduino Board and Labview, " International Journal of Power Electronics and Drive System (IJPEDS), Vol. 9, No. 1, March 2018, pp. 98-104

[4] B. Liu, S. Duan and T. Cai, "Photovoltaic DC-Building-Module-Based BIPV System-Concept and Design Considerations," in IEEE Transactions on Power Electronics, vol. 26, no. 5, pp. 1418-1429, May 2011.

[5] REN21, "Renewables 2015: Global status report," 2014.

[6] A. G. Garganeev, R. Aboelsaud, and A. Ibrahim, "A Novel Predictive Control Algorithm For Autonomous Power Supply Systems," in Proceedings of the 4th International Conference on Frontiers of Educational Technologies ICFET'18, 2018, pp. 170-175.

[7] T. Kawamura et al., "Analysis of MPPT characteristics in photovoltaic power system," Sol. Energy Mater. Sol. Cells, 1997.

[8] C. Thulasiyammal and S. Sutha, "Design and comparative analysis of dc-dc boost and single-ended primaryinductance converter converters using solar powered maximum power point tracking algorithms," Am. J. Appl. Sci., 2014.

[9] N. Femia, G. Petrone, G. Spagnuolo, and M. Vitelli, "A technique for improving P\&O MPPT performances of double-stage grid-connected photovoltaic systems," IEEE Trans. Ind. Electron., 2009.

[10] F. Liu, Y. Kang, Z. Yu, and S. Duan, "Comparison of P\&O and hill climbing MPPT methods for grid-connected PV converter," in 2008 3rd IEEE Conference on Industrial Electronics and Applications, ICIEA 2008, 2008.

[11] A. Safari and S. Mekhilef, "Incremental conductance MPPT method for PV systems," in Canadian Conference on Electrical and Computer Engineering, 2011.

[12] H. Patel and V. Agarwal, "MATLAB-based modeling to study the effects of partial shading on PV array characteristics," IEEE Trans. Energy Convers., 2008.

[13] K. Chen, S. Tian, Y. Cheng, and L. Bai, "An improved MPPT controller for photovoltaic system under partial shading condition," IEEE Trans. Sustain. Energy, 2014.

[14] S. Obukhov, A. Ibrahim, and Raef Aboelsouad, "Maximum Power Point Tracking OF Partially Shading PV system Using Particle Swarm Optimization," 4th Int. Conf. Front. Educ. Technol. Proc. , Moscow, June 25-27, 2018. New York ACM, pp. 161-165, 2018.

[15] C. Ben Salah and M. Ouali, "Comparison of fuzzy logic and neural network in maximum power point tracker for PV systems," Electr. Power Syst. Res. Vol.81 (1), PP. $43-50$ (2011).

[16] Syafaruddin, E. Karatepe, and T. Hiyama, "Artificial neural network-polar coordinated fuzzy controller based maximum power point tracking control under partially shaded conditions," IET Renew. Power Gener. Vol.3 (2) (2009).

[17] R. Ramaprabha and B. Mathur, "Genetic Algorithm Based Maximum Power Point Tracking for Partially Shaded Solar Photovoltaic Array," Int. J. Res. Rev. Inf. Sci. 2(1), PP. 161-163 (2012).

[18] S. Obukhov and R. A. Ibrahim, A, "Maximum Power Point Tracking OF Partially Shading PV system Using Particle Swarm Optimization," 4th Int. Conf. Front. Educ. Technol. Proc. , Moscow, June 25-27, 2018 - New York ACM, pp. 161-165 (2018).

[19] K. Sundareswaran, P. Sankar, P. S. R. Nayak, S. P. Simon, and S. Palani, "Enhanced energy output from a PV system under partially shaded conditions through artificial bee colony," IEEE Trans. Sustain. Energy. 6(1), pp. 198-209 (2015).

[20] J. Ahmed and Z. Salam, "A Maximum Power Point Tracking (MPPT) for PV system using Cuckoo Search with partial shading capability," Appl. Energy, 2014.

[21] Laagoubi, T., M. Bouzi, and M. Benchagra, “ MPPT and Power Factor Control for Grid Connected PV Systems with Fuzzy Logic Controllers, ” International Journal of Power Electronics and Drive Systems (IJPEDS),. 9(1): p. 105- 113,2018

[22] S. Jafari, O. Bozorg-Haddad, and X. Chu, "Cuckoo optimization algorithm (COA)," in Studies in Computational Intelligence, 2018.

[23] A. M. Reynolds and M. A. Frye, "Free-flight odor tracking in Drosophila is consistent with an optimal intermittent scale-free search," PLoS One, 2007.

[24] X. S. Yang and S. Deb, "Cuckoo Search via Lévy Flight," Nature \& Biologically Inspired Computing, 2009. NaBIC 2009. World Congress on. 2009.

[25] H. Soneji and R. C. Sanghvi, "Towards the improvement of Cuckoo search algorithm," in Proceedings of the 2012 World Congress on Information and Communication Technologies, WICT 2012, 2012.

Int J Pow Elec \& Dri Syst, Vol. 10, No. 2, June 2019 : 1081 - 1089 


\section{BIOGRAPHIES OF AUTHORS}

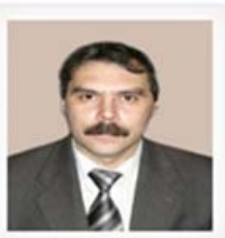

S. Obukhov (Professor) was born in Tomsk, Russia in 1963. In 1989 he defended his thesis and received $\mathrm{PhD}$ degree from National Research Tomsk Polytechnic University, Tomsk, Russia and continued his career at the department in the position of senior researcher. The research interest covers different types of renewable energy.E-mail: serob99@mail.ru.

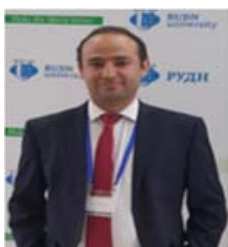

A. Ibrahim (Teaching Assistant) was born in EL-Sharkia, Egypt in 1987. He received the B.Sc. from the Faculty of Engineering, Zagazig University, Egypt in 2009. And M.Sc. from the Faculty of Engineering, Zagazig University, Egypt in 2013. Now he is teaching assistant in National Research Tomsk Polytechnic University, Tomsk, Russia. The research interest covers different types of renewable energy, particle swarm optimization, neural networks, cuckoo optimizations and its applications in renewable energy. He is a student member in IEEE. E-mail: ibragim@tpu.ru.

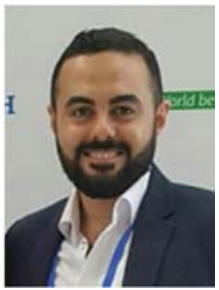

Raef Aboelsaud (Teaching Assistant) was born in Zagazig, Egypt, in 1987. He received the B.Sc. degree (with honors) and the M.Sc. degree in electrical engineering from Zagazig University, Zagazig, Egypt, in 2009 and 2013, respectively. He is currently working toward the Ph.D. Degree in electrical engineering at Tomsk Polytechnic University, Tomsk, Russia. His current research interests include power electronic converters and control systems applied to renewable energy conversion and energy storage, He is a student member in IEEE. Email: rsahmed@eng.zu.edu.eg. 